\title{
Visceral leishmaniasis in Southern Rio de Janeiro State and the risk of propagation to São Paulo State, Brazil
}

\author{
Mauro Celio de Almeida Marzochi[1]
}

[1]. Laboratório de Pesquisa Clinica e Vigilância em Leishmanioses, Instituto Nacional de Infectologia Evandro Chagas, Fundação Oswaldo Cruz, Rio de Janeiro, Rio de Janeiro, Brasil.

\section{Introduction}

Visceral leishmaniasis (VL), also known as American VL, or neotropical kala-azar, is an epidemic zooanthroponosis endemic to Brazil. It affects both rural and peri-urban areas, and can also spread into urban areas. The causative agent is Leishmania infantum chagasi, and the principal vector is the sand fly species Lutzomyia longipalpis. Domestic dogs are the main host for the insect vector, and once infected can transmit the protozoan infection to other canids and humans ${ }^{(1)}$.

Human and canine VL propagated by L. longipalpis has recently been observed in Rio de Janeiro City, the Middle Paraíba Valley and the Costa Verde Fluminense. This has exposed the contiguous Paraíba Valley (Vale do Paraiba) and the North Coast (Litoral Norte), in the neighboring São Paulo State, to new infections. Although a similar situation occurred in the 1990s in western São Paulo State, during which the infection traversed highways and railways connecting the region to Mato Grosso do Sul State, the latter was already endemic for VL.

The current complexity of urban VL transmission poses new challenges, and there is an urgent need for new strategies to control the spread of infection. The increased circulation of human populations and infected dogs, and greater distribution of the sand fly vector, which is also influenced by human activities, need to be considered ${ }^{(1)}$.

\section{Visceral leishmaniasis in Brazil}

The first VL cases in Brazil were reported in the 1930s in the Northeast and North regions. The disease remained in these rural areas until the last three decades, after which existing endemic areas expanded and new foci emerged in other regions. VL has since spread with a tendency towards urban infections. The Ministry of Health currently reports more than 3,000 human cases per year in Brazil, with a geographic distribution ranging from the northern Amazon to the southern Paraguayan border, and the Central-West region. However, the disease persists predominantly in the northeast ${ }^{(2)}$. Human VL

Corresponding author: Dr. Mauro Celio de Almeida Marzochi. e-mail: mauro.marzochi@ini.fiocruz.br

Received 1 April 2016

Accepted 14 April 2016 is currently distributed across 21 Brazilian states, and these include all five major geographic regions. In 2010, the Northeast reported $47.1 \%$ of cases, followed by the North $(18 \%)$, Southeast $(17.8 \%)$, Central-west $(8.6 \%)$, and South $(0.1 \%)$. The national case-fatality rate is approximately $7 \%{ }^{(2)}$.

In Brazil, endemic VL is more (62.2\%) frequent in males. The predominance of VL in children under 10 years of age, which formerly represented $80 \%$ of cases, has decreased to approximately $45 \%$ as the disease spreads to new areas ${ }^{(2)}$.

Since the 1970s, Minas Gerais and Espírito Santo States in Southeast Brazil have displayed an increasingly endemic pattern of human and canine VL cases, following the pattern of the Rio Doce Valley. In Rio de Janeiro City, the disease first appeared in the late 1970s in Bangu neighborhood, situated in the West Zone. Subsequently, VL began to spread towards the more heavily urbanized areas of the city in a process of rural-tourban transition. Since the 1980s, VL has become urbanized in the metropolitan areas of Teresina, Belo Horizonte, and Montes Claros, and this was followed in the 1990s by municipalities in the Western São Paulo State. In particular, Araçatuba and Bauru have been affected, and these have close commercial relations with the endemic municipalities in Mato Grosso do Sul State of Campo Grande and Três Lagoas in the Central-West region ${ }^{(1)}$.

The extensive urbanization of VL in important Brazilian economic hubs has led to unnatural transmission routes, through blood transfusion, organ transplantation, and needles and syringes shared by intravenous drug users. The latter has resulted in co-infections of clinically asymptomatic Leishmania with human immunodeficiency virus (HIV), resulting in high reactivation and case-fatality rates due to more difficult diagnosis and treatment resistance. These factors are also important in the development of new approaches to VL prevention and control ${ }^{(1)}$.

\section{Visceral leishmaniasis in Rio de Janeiro City}

Human and canine VL cases associated with the presence of L. longipalpis were initially detected in Rio de Janeiro City in August 1977. By August 2006, there were 87 confirmed cases with 9 deaths, and 2 of the deceased individuals were co-infected with $\mathrm{HIV}^{(3)}$.

All of these cases occurred in peri-urban areas close to the Pedra Branca and Gericinó Massifs in neighborhoods located in the West Zone of the city. The cases occurred predominantly 
on the massif slopes in environments with abundant vegetation, various sand fly species (especially L. longipalpis), and dogs infected with L. i. chagasi $^{(3)}$.

The last 2 cases in these areas occurred in 2006 in the Gericinó and Campo Grande neighborhoods, respectively. The majority (65.5\%) of patients were more than 5 years old, with a predominance of males $(61.5 \%)$, although the difference in gender frequency was only observed in individuals older than 14 years $^{(3)}$.

Control strategies were based on the identification, diagnosis, and treatment of human cases, serological surveys, identification, and culling of seropositive dogs, and vector control using insecticides.

In the areas where VL emerged in Rio de Janeiro, no new cases were reported from 2007-2015. However, an alarming number of seropositive dogs remain ${ }^{(3)}$.

More recently, both asymptomatic and symptomatic canine infections have been detected in urban neighborhoods of the city including Laranjeiras ${ }^{(4)}$ and Caju (Secretaria Municipal de Saúde do Rio de Janeiro, 2013). In the large São Francisco Xavier Cemetery in Caju, there is a kennel with dozens of dogs, the majority of which are infected with L. i. chagasi. Since 2010, L. longipalpis has also been detected there ${ }^{(5)}$.

These observations preceded the occurrence of one new human case in Caju during January 2013. A 29-year-old woman lived in a community adjacent to the cemetery and was treated in the terminal phase due to late diagnosis, but was nevertheless cured.

\section{Visceral leishmaniasis in Rio de Janeiro State}

In the other areas of Rio de Janeiro State, canine VL has recently been detected in the municipalities of Angra dos Reis, Mangaratiba, Paraty, Maricá, Niterói, Barra Mansa, and Volta Redonda. Human VL re-emerged in Barra Mansa in 2010, with 9 cases reported by 2013 ( 7 adults and 2 children). Four of these infected individuals died, the first of which was diagnosed post-mortem $^{(6)}$ in Volta Redonda. Of the remaining 3 cases, 2 adults were treated and cured, and one child died.

Since 2014, at least 4 additional human cases have been diagnosed in Paraty and Angra dos Reis, with one death in the latter municipality (Secretaria Estadual de Saúde, November 2015: unpublished data).

\section{Final remarks}

The emergence of VL demonstrates a close relationship with human and canine circulation, disordered land occupation, deforestation, and poverty. The steady drop in VL cases in Rio de Janeiro City, and the absence of human cases in peri-urban areas, is attributable to rigorous epidemiological surveillance in high-risk areas for more than 30 years. In addition, active case search, emphasis on education, especially backyard cleaning, vector control strategies including the use of insecticides (organochlorides until 1991, then organophosphates and pyrethroids consecutively), and culling of seropositive dogs has aided in the control of VL.

However, numerous areas in Rio de Janeiro still persistently demonstrate the same conditions as when VL developed in the 1980s, although these areas have not reported any VL cases to date. In contrast, $\mathrm{VL}$ foci currently continue to emerge in central areas of Rio de Janeiro and other Brazilian urban regions, despite decent housing and previous absence of L. longipalpis.

The current situation poses several important challenges. Firstly, there is a need for a better understanding of the factors facilitating the establishment and spread of both canine and human VL in Brazil. This is complicated by complex ecoepidemiological patterns involving environmental, social, and economic factors, and a lack of knowledge regarding variables that sustain VL emergence. Secondly, prioritization of research regarding the establishment, adaptation, and persistence of L. longipalpis are required. These should be aimed at preventing introduction of the vector into disease-free areas, by considering passive transportation of eggs, larvae, and pupae in organic materials like grain, animal feces, and organic fertilizers ${ }^{(1)}$.

Visceral leishmaniasis requires early diagnosis, preferably through the active search for human and canine cases in high-risk areas by primary care physicians, veterinarians, and community health workers, with subsequent referral of suspected cases to specialized centers. Community health workers could question patients and residents in suspected VL areas concerning their knowledge of individuals with fever (usually low-grade, either continuous or intermittent, lasting more than 3-4 weeks). This may be indicative of VL, and patients identified through these means could then be referred for diagnostic testing.

Definitive diagnosis still requires invasive aspiration biopsy of the bone marrow, spleen, or lymph nodes, and required a positive Leishmania culture.

In Rio de Janeiro State, the trend towards propagation of human and canine VL towards the Middle Paraíba Valley and Costa Verde requires the urgent implementation of a VL Epidemiological Surveillance and Control Program. In these areas, canine infection is also associated with presence of L. longipalpis, and renders the region vulnerable to VL. Likewise, greater attention should be focused on VL prevention in the Paraíba Valley and North Coast (Litoral Norte) in São Paulo State. Of particular importance, these regions are extensions of the same ecosystem connected to Southern Rio de Janeiro State by the President Dutra Highway and the Central Brazilian Railway.

\section{ACKNOWLEDGMENTS}

We would like to thank the Conselho Nacional de Desenvolvimento Científico e Tecnológico/Instituto Nacional de Infectologia Evandro Chagas, Fundação Oswaldo Cruz (CNPq/INI-FIOCRUZ), to Dr. Aline Fagundes and all the Laboratório de Pesquisa Clinica e Vigilancia em Leishmanioses (LAPCLIN-Vigileish) staff who provided assistance with this study.

\section{CONFLICT OF INTEREST}

The authors declare that there is no conflict of interest. 


\section{FINANCIAL SUPPORT}

Mauro Celio de Almeida Marzochi is a Pesquisador Sênior CNPq/INI-FIOCRUZ.

\section{REFERENCES}

1. Marzochi MCA, Marzochi KBF, Fagundes A, Conceição-Silva F. A questão do controle das leishmanioses no Brasil. In: ConceiçãoSilva F, Alves CR (org.). Leishmanioses do continente americano. ISBN: 978-85-7541-439-2, Editora FIOCRUZ, 2014. 512 p.

2. Ministério da Saúde. Leishmaniose Visceral. 2010. Available at: $<$ http://portal.saude.gov.br/portal/saude/profissional/area.cfm?id area $=1561>$. Accessed on April 27, 2012.
3. Marzochi MCA, Fagundes A, Andrade MV, Souza MB, Madeira MF, Mouta-Confort E, et al. Visceral leishmaniasis in Rio de Janeiro, Brazil: eco-epidemiological aspects and control. Rev Soc Bras Med Trop 2009; 42: 570-580.

4. Figueiredo FB, Barbosa Filho CJL, Schubach EYP, Pereira SA, Nascimento LD, Madeira MF. Relato de caso autóctone de leishmaniose visceral canina na zona sul do município do Rio de Janeiro. Rev Soc Bras Med Trop 2010; 43:98-99.

5. Silva GAR, Boechat TO, Ferry FRA, Pinto JFC, Azevedo MCVM, Carvalho RS, et al. Primeiro caso de leishmaniose visceral humana de transmissão autóctone no centro urbano do Rio de Janeiro: relato de caso. Rev Inst Med Trop São Paulo 2014; 56: 81-84.

6. Pimentel MIF, Alves ELM, Silva MHFF, Moza PG, de Almeida PMP, Cunha CS, et al. High visceral leishmaniasis mortality rate in Barra Mansa, a new area of visceral leishmaniasis transmission in the State of Rio de Janeiro, Brazil. Rev Soc Bras Med Trop 2014; 47:521-552. 